\title{
Immunization against Porphyromonas gingivalis for Prevention of Experimentally Induced Periodontitis in Rats
}

\author{
Parviz Torkzaban ${ }^{1}$, Morad Hedayatipanah ${ }^{2}$, Alireza Zamani ${ }^{3}$, Rasoul Yousefimashouf ${ }^{4}$, Javad Faradmal ${ }^{5}$
}

\begin{abstract}
Aim: Periodontitis is an inflammatory disease causing destruction of tooth-supporting structures. It is often caused by gram-negative microorganisms such as Porphyromonas gingivalis ( $P$. gingivalis). Common treatments for periodontitis are often nonspecific and include mechanical plaque removal and surgery. This study aimed to assess the amount of bone loss and antibody titer against $P$. gingivalis in rats.

Materials and methods: This in vitro experimental study was conducted on 66 Surrey rats free of black pigmented pathogens, which were randomly divided into six groups of 11. Groups I and II were vaccinated with formalin-killed whole-cell (FKWC) P. gingivalis with incomplete Freund's adjuvant as the vaccine carrier, and groups III and IV were vaccinated with incomplete Freund's adjuvant and PG buffer. Groups V and $\mathrm{VI}$ were considered as positive and negative controls, respectively. Three weeks later, they were vaccinated with a booster dose. At 28 days, groups I, III, and V were inoculated with viable P. gingivalis (ATCC 33277) four times at 48-hour intervals for induction of periodontitis. One week after booster dose administration and two weeks after oral inoculation of bacteria, serum and saliva samples were obtained for assessment of antibody titer. Ten weeks after final bacterial inoculation, the serum and saliva samples were obtained to assess antibody titer, and subgingival plaque samples were obtained from the maxillary second molar site to assess the bacterial count. The rats were then sacrificed to assess bone loss. Results: Serum and saliva antibody titers in groups I and II were significantly different from those in other groups one week after booster dose and two and 10 weeks after oral inoculation of bacteria $(p<0.001)$. In terms of bone loss and bacterial count in the subgingival plaque, group I was not significantly different from the negative control group and groups II, IV, and VI ( $p>0.99)$, but had a significant difference with the positive control (group V) and group III ( $p<0.001)$.
\end{abstract}

Conclusion: This study showed successful immunization against $P$. gingivalis, which increased serum IgG and saliva IgA titers, limited the colonization of $P$. gingivalis in subgingival plaque, and restricted the alveolar bone loss.

Keywords: Bone loss, Immunization, Periodontitis, Porphyromonas gingivalis, Rats.

World Journal of Dentistry (2019): 10.5005/jp-journals-10015-1639

\section{INTRODUCTION}

Periodontitis is an infectious disease causing inflammation of the tooth-supporting structures as well as progressive attachment loss and bone loss. It can lead to eventual tooth loss as well. ${ }^{1,2}$ Formation of microbial plaque, periodontal inflammation, attachment loss, and alveolar bone loss are the characteristics of periodontal disease. ${ }^{1}$ Periodontal pocket formation is a consequence of periodontal disease unless attachment loss occurs in combination with gingival recession. ${ }^{1,2}$ According to the American Academy of Periodontology, periodontitis is divided into three main groups chronic periodontitis, aggressive periodontitis, and periodontitis as a manifestation of systemic disease. ${ }^{1}$ The current study focused on chronic periodontitis. Clinical findings in patients with untreated chronic periodontitis include supra- and subgingival plaque accumulation, which is often accompanied by calculus formation, gingival inflammation, pocket formation, attachment loss, alveolar bone resorption, and pus formation. Chronic periodontitis increases in prevalence and severity with age, and it generally affects both genders equally. ${ }^{1,2}$

Attachment loss and bone resorption are correlated with an increase in the count of subgingival Gram-negative microorganisms and periodontal pathogens. The plaque accumulation red complex bacteria including P. gingivalis, Treponema denticola, and Tannerella forsythia often cause attachment loss and bone loss in chronic periodontitis. ${ }^{1,2}$ Isolation of these bacteria resulted in development of specific plaque hypothesis in development of chronic periodontitis. According to this hypothesis, although the count of
1,2Department of Periodontics, Faculty of Dentistry, Hamadan University of Medical Sciences, Hamadan, Iran

${ }^{3}$ Department of Immunology, Hamadan University of Medical Sciences, Hamadan, Iran

${ }^{4}$ Department of Microbiology, Hamadan University of Medical Sciences, Hamadan, Iran

${ }^{5}$ Modeling of Noncommunicable Diseases Research Center and Department of Biostatistics, School of Public Health, Hamadan University of Medical Sciences, Hamadan, Iran

Corresponding Author: Morad Hedayatipanah, Department of Periodontics, Faculty of Dentistry, Hamadan University of Medical Sciences, Hamadan, Iran, Phone: +98 9188413990, e-mail: dr.hedayatipanah@yahoo.com

How to cite this article: Torkzaban $P$, Hedayatipanah $M$, et al. Immunization against Porphyromonas gingivalis for Prevention of Experimentally Induced Periodontitis in Rats. World J Dent 2019;10(3):170-176.

Source of support: Hamadan University of Medical Sciences Research Center

Conflict of interest: None

gram-negative microorganisms in subgingival plaque increases, the increased proportion of red complex bacteria and some other microorganisms probably causes bone loss and attachment loss.,

Plaque accumulation is the main factor initiating periodontal destruction. Thus, any factor facilitating plaque accumulation or complicating plaque removal and oral hygiene practice may

o The Author(s). 2019 Open Access This article is distributed under the terms of the Creative Commons Attribution 4.0 International License (https://creativecommons. org/licenses/by-nc/4.0/), which permits unrestricted use, distribution, and non-commercial reproduction in any medium, provided you give appropriate credit to the original author(s) and the source, provide a link to the Creative Commons license, and indicate if changes were made. The Creative Commons Public Domain Dedication waiver (http://creativecommons.org/publicdomain/zero/1.0/) applies to the data made available in this article, unless otherwise stated. 
contribute to occurrence of periodontal disease. These factors include calculus, subgingival restoration margins, overhang of restorations, carious lesions extending subgingivally, exposed furcations due to attachment loss, teeth with crowding, and grooves or concavities on root surfaces. ${ }^{1,2}$ Subgingival bacteria release toxic substances and directly cause tissue destruction. They also trigger inflammatory and immunity responses that cause tissue destruction. $^{1-3}$

Conventional treatment of periodontitis is nonspecific and mainly based on mechanical removal of plaque and calculus and surgery. ${ }^{4}$ This modality is costly and not favored by patients and also has variable prognosis. ${ }^{4}$ Currently, $P$. gingivalis is the main periodontal pathogen involved in chronic periodontitis. ${ }^{3,5-8}$

Its subgingival implantation in rats, mice and mammals results in initiation and progression of gingival and periodontal disease. ${ }^{4,6,7}$ Isolation of a specific microorganism as the main culprit for periodontal disease can result in targeted treatments based on specific virulence factors. Porphyromonas gingivalis is a rod-shaped, asaccharolytic, nonmobile, anaerobic Gramnegative microorganism from the family of black pigmented microorganisms. It can stimulate the humoral immune response of the host via several virulence factors such as lipopolysaccharides, cysteine proteases known as gingipains, fimbria, extracellular DNA, and the ability to invade tissues (Table 1). ${ }^{1,2,4,9,10}$

$P$. gingivalis produces two classes of cysteine proteases that have been implicated in periodontal pathogenesis. These are known as gingipains, and they include the lysine-specific gingipain $\mathrm{Kgp}$ and the arginine-specific gingipains $\mathrm{RgpA}$ and $\mathrm{RgpB}$. The gingipains can modulate the immune system and disrupt immuneinflammatory responses, potentially leading to increased tissue breakdown. Gingipains can reduce the concentrations of cytokines in cell culture systems, and they digest and inactivate TNF-a. The gingipains can also stimulate cytokine secretion via the activation of protease-activated receptors (PARs). ${ }^{1}$

Fimbria stimulates the immune system and induces the release of IL-6. The main components of fimbria of $P$. gingivalis include FiMA, which induces the release of NfKB and IL-8 from gingival epithelial cells through TLR2. Also, FiMA stimulates monocytes and induces the release of IL- $6, \mathrm{IL}-8$, and TNF-alpha. The fimbria of $P$. gingivalis affects the CR3 complement receptor to activate intracellular signaling pathways and prevent the production of IL-12 by TLR2. IL-12 plays an important role in activating natural killer cells and CD8+ cytotoxic T cells. These cells eliminate host tissues infected with $P$. gingivalis such as epithelial cells. Thus, inhibition of CR3 receptor eliminates $P$. gingivalis via IL-12 and inhibits its virulence. Thus, fimbria of $P$. gingivalis plays a role in changing and stimulating the immune response in periodontium. ${ }^{1,2,4,9,10}$
Vaccination of mammals with killed whole cells of $P$. gingivalis has been shown to decrease the progression of periodontitis caused by oral microflora such as $P$. gingivalis. ${ }^{4}$ Moreover, decrease in bone loss has been demonstrated in rats with periodontitis following their vaccination with whole cells of $P$. gingivalis. ${ }^{4}$

Animal studies have also supported the use of $P$. gingivalis vaccine as an adjunct for treatment of chronic periodontitis.

Thus, we used $P$. gingivalis since it stimulates the humoral immune response through several virulence factors such as arginine and lysine cysteine proteases as well as fimbria.

We used formalin-killed whole-cell (FKWC) $P$. gingivalis for vaccination of rats to assess its efficacy to induce an immune response against oral inoculation of viable $P$. gingivalis and prevent bone loss, hoping to take a step forward in developing a vaccine for human periodontitis.

\section{Materials and Methods}

This study was conducted at the Hamadan University of Medical Science, after obtaining ethical approval from the ethics committee of Hamadan University.

\section{Obtaining $P$. gingivalis}

In this study, P. gingivalis (ATCC33277) was obtained from SinaClone Company (Tehran, Iran). According to a previous study and the manufacturer's instructions, ${ }^{4,5}$ the bacteria were stored at room temperature in lyophilized form. ${ }^{4,11}$ Cultured bacteria were maintained in a sheep blood agar plate containing $10 \mathrm{v} \%$ lyzed sheep blood, $15 \mu \mathrm{g} / \mathrm{mL}$ hemin, and $1 \mu \mathrm{g} / \mathrm{mL}$ menadione and stored in gas pack $A$ anaerobic jar at $37^{\circ} \mathrm{C}$. A three- to five-day culture of $P$. gingivalis (ATCC33277) was transferred to a brain-heart infusion broth enriched with $15 \mu \mathrm{g} / \mathrm{mL}$ hemin, $1 \mu \mathrm{g} / \mathrm{mL}$ menadione, cysteine $(1 \mu \mathrm{L} / \mathrm{mL})$, and $0.5 \mathrm{~g} / \mathrm{L}$ chloric acid at $37^{\circ} \mathrm{C} .^{3}$ The pure culture was Gram-stained and the morphology of colonies was evaluated, which indicated Gram-negative coccobacilli. The brain-heart infusion broth containing bacteria was centrifuged at $10,000 \times g$ for 30 minutes at $4^{\circ} \mathrm{C}$ and the supernatant was removed. The cell sediment was then made up to a final concentration of $2.5 \times 10^{11}$ colony-forming units (CFUs)/mL by adding PG buffer $(150 \mathrm{mM}$ $\mathrm{NaCl} \mathrm{pH}$ of 7.8, $50 \mathrm{mM}$ Tris- $\mathrm{HCl}, 0.5 \mathrm{~g} / \mathrm{L}$ cysteine, $\left.10 \mathrm{mM} \mathrm{MgSO}_{4}\right)$ at $4^{\circ} \mathrm{C}$ containing $5 \%$ carboxymethyl cellulose with low viscosity for inoculation to the oral cavity of animals. ${ }^{4}$

\section{Preparation of Formalin-Killed Whole-Cell (FKWC) P. gingivalis (ATCC33277)}

Bacteria in equal volume with $0.5 \%$ formal saline were incubated overnight in a shaking incubator. Sterile PG buffer (10 times

Table 1: Virulence factors of Porphyromonas gingivalis that interact with the immune system

\begin{tabular}{ll}
\hline Proteases (gingipains) & $\begin{array}{l}\text { Degradation of signaling molecules (CD14) and cytokines } \\
\text { (e.g., interleukin-1 } \beta \text {, interleukin-6) }\end{array}$ \\
$\begin{array}{l}\text { Cell invasion capabilities } \\
\text { Inhibition of interleukin-8 secretion }\end{array}$ \\
$\begin{array}{l}\text { Antagonism of the stimulatory effects of lipopolysaccharides from } \\
\text { other species; no upregulation of E-selectin }\end{array}$ \\
Fimbriae & Inhibition of interleukin-12 secretion in macrophage \\
Cell surface polysaccharides & Resistance to complement \\
Short-chain fatty acids & Induction of apoptosis in host cells \\
Extracellular DNA & $\begin{array}{l}\text { Play a role in the development and structure of the biofilms } \\
\text { formed by oral bacteria, and it has been identified as an important } \\
\text { component of the matrix in a number of bacterial biofilms }\end{array}$ \\
\end{tabular}


the volume of cells) was added to the cells and the suspension was centrifuged at $10,000 \times g$ for 10 minutes. The supernatant was discarded and cell sediments were gently immersed in PG buffer (20 times the cell sediment volume) and centrifuged for 10 minutes. After discarding the supernatant, the cells were immersed in sterile PG buffer to obtain $10^{10} \mathrm{CFUs}$ per $0.1 \mathrm{~mL}$ of PG buffer containing $5 \%$ carboxymethyl cellulose. For immunization, the cell suspension was mixed with incomplete Freund's adjuvant (IFA) in 1:1 ratio and injected into rats as varied combinations were used. ${ }^{4,5,11}$

After obtaining ethical approval from the ethics committee of our university, 66 male Surrey rats free from black pigmented pathogens were randomly divided into six groups of 11 and housed in cages.

In the beginning of the study to confirm that all rats are free from black pigmented microorganisms, plaque samples of all rats were obtained and cultured in a sheep blood agar plate supplemented with $400 \mu \mathrm{g} / \mathrm{mL}$ kanamycin.

Group I: Rats were vaccinated with FKWC $P$. gingivalis $\left(10^{10}\right)$ and IFA in 1:1 ratio and were then inoculated with $P$. gingivalis.

Group II: Rats were vaccinated with FKWC $P$. gingivalis $\left(10^{10}\right)$ and IFA in 1:1 ratio, but were not subjected to inoculation with P. gingivalis.

Group III: Rats were vaccinated with IFA + PG buffer and were inoculated with P. gingivalis.

Group IV: Rats were vaccinated with IFA + PG buffer, but were not inoculated with $P$. gingivalis.

Group V: No vaccination was performed for this group, and rats were only subjected to inoculation with $P$. gingivalis (positive control).

Group VI: No vaccination was performed for this group, and rats were not subjected to inoculation with $P$. gingivalis (negative control).

Four-week-old rats in groups I-IV were vaccinated with $0.2 \mathrm{~mL}$ of the respective suspension via a subcutaneous injection at the back of their neck. All groups were vaccinated again with the same dose three weeks after the first vaccination (booster). One week after booster injection, rats were anesthetized with ether and blood was collected from their retrobulbar vascular network using a capillary tube. After centrifugation, serum was stored at $-70^{\circ} \mathrm{C}$. Saliva samples were also obtained using a $1 \mathrm{~mL}$ sampler and after centrifugation, they were stored at $-70^{\circ} \mathrm{C}$.

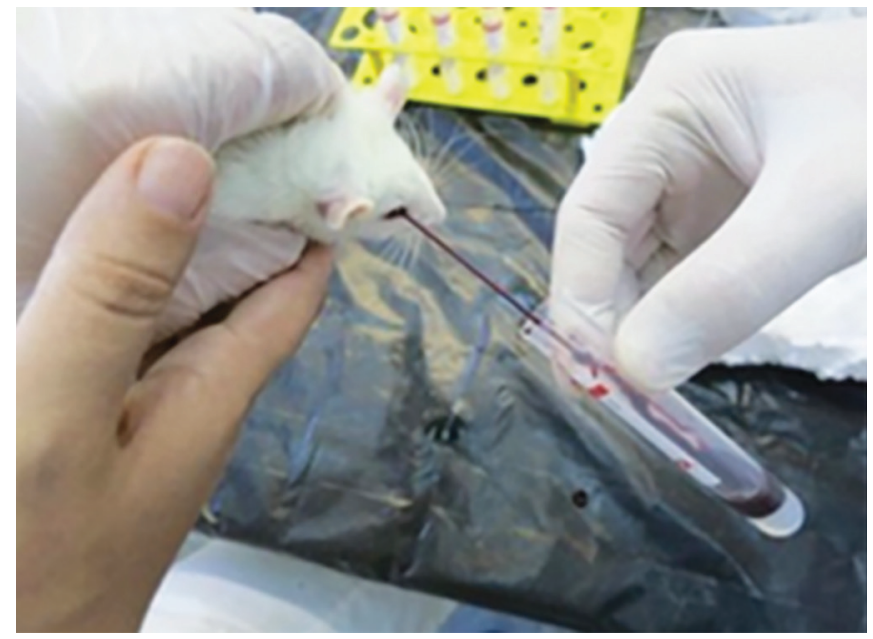

Fig. 1: Collection of blood from the retrobulbar vascular network
At 28 days after sampling, all animals in groups I, III, and V were inoculated with $P$. gingivalis. This was repeated four times at 48-hour intervals. Groups II, IV, and VI were not inoculated with bacteria. Animals were inoculated with viable $P$. gingivalis using a $1 \mathrm{~mL}$ insulin syringe fitted to a 16-gauge gavage tube. Each rat was inoculated with $1 \mathrm{~mL}$ of $P$. gingivalis suspension as follows: $0.75 \mathrm{~mL}$ of the suspension was gavaged into the pharynx; $0.2 \mathrm{~mL}$ of the suspension was inoculated to the gingiva at the site of molar tooth ( $50 \mu \mathrm{L}$ per each quadrant) and $50 \mu \mathrm{L}$ was inoculated to the colorectal area.

Two weeks and ten weeks after final inoculation of viable bacteria, saliva and serum samples were obtained again to assess antibody titers (Figs 1 and 2). Samples were also taken from the subgingival plaque at the maxillary second molar site to assess the bacterial count in the subgingival plaque at ten weeks.

To collect the saliva, pilocarpine nitrate $(5 \mathrm{mg} / \mathrm{kg})$ was injected at the back of their neck for parasympathetic stimulation. Saliva was collected by a $1 \mathrm{~mL}$ sampler. Collected saliva was stored in 1.5-mL micro-centrifuge tubes on ice until centrifugation. After centrifugation at $5000 \mathrm{~g}$ for 20 minutes, the supernatant was frozen at $-70^{\circ} \mathrm{C}$ for further analyses. Specimens were stored at $-20^{\circ} \mathrm{C}$ until use.

Antibody in serum and saliva samples was analyzed using an ELISA kit. To assess serum and saliva total antibody titer, an ELISA Ensemble kit (Alpha Diagnostic, USA) specific for rats (\#80155) was used. To determine the class of antibody used, IgG FC- and IgA FC HRP-conjugated goat anti-rat (KOMA Biotech) kit was used. The absorbance value was the ELISA plate measured/read at 450 nanometers ( $\mathrm{nm}$ ).

To assess horizontal bone loss, the rats were sacrificed and their maxilla was resected. The specimens were boiled in water for 5 minutes and then the flesh was separated from bone using a curette. The specimens were then immersed in sodium hypochlorite for 4 hours for separation of tissue residues and disinfection. To mark the cementoenamel junction, specimens were immersed in methylene blue $(1 \mathrm{~g} / 100 \mathrm{~mL})$ for one minute and were then evaluated under a stereomicroscope at $\times 25$ magnification (Fig. 3 ). To standardize the images, the tip of buccal and palatal cusps had to be superimposed and the occlusal surface should not be seen. After calibration, horizontal bone loss from the cementoenamel junction to bone crest was linearly measured in microns at mesiobuccal and distobuccal sites using MIP4 software (Nahamin Pardazan Asia Co.).

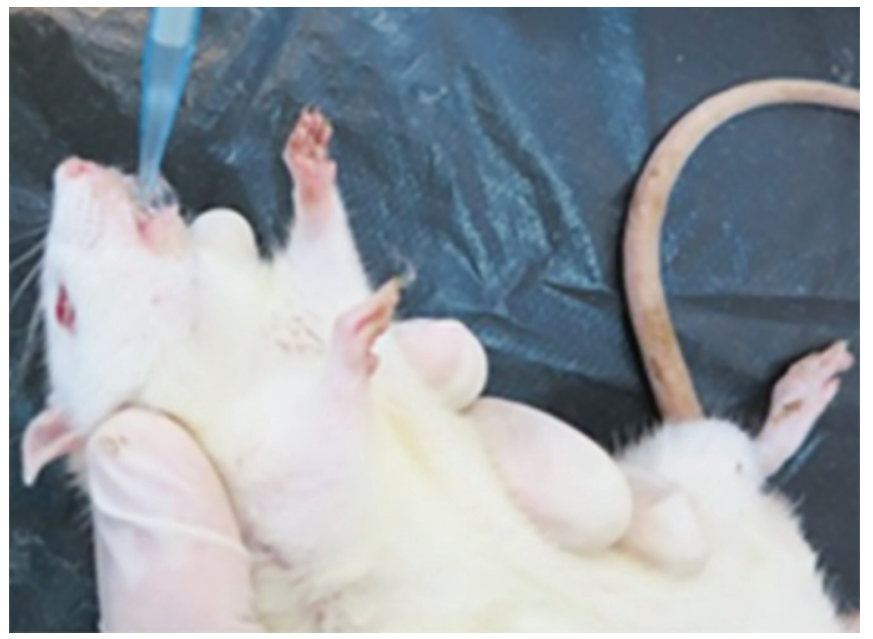

Fig. 2: Collection of saliva using a $1 \mathrm{~mL}$ sampler 


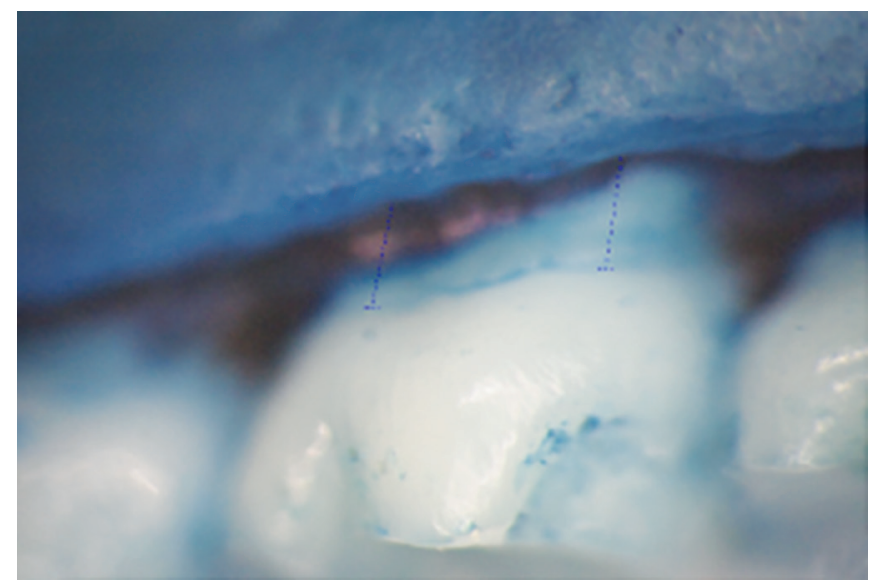

Fig. 3: Horizontal bone loss from the cementoenamel junction to bone crest was linearly measured

The mean value was considered as horizontal bone loss for each specimen.

A thin paper point was used for subgingival plaque sampling. The collected sample was transferred to a sodium thioglycolate culture medium containing $15 \mu \mathrm{g} / \mathrm{mL}$ of hemin and $1 \mu \mathrm{g} / \mathrm{mL}$ of menadione. The samples were transferred to lab within 30 minutes for culture in sheep blood agar containing $400 \mu \mathrm{g} / \mathrm{mL}$ kanamycin. Culture plates were placed in a gas pack $A$ anaerobic jar. After five days, the plates were evaluated for the presence of $P$. gingivalis. First, each colony was Gram-stained. P. gingivalis colonies are shiny, convex, dark brown to black in color, have a bad odor, form a mucoid plaque and are without florescence. They are in the form of bacilli and coccobacilli. The presence of $P$. gingivalis was also confirmed by biochemical tests. The catalase test was negative and the indole test was positive. Bacteria were sensitive to vancomycin disc (presence of growth inhibition zone) and resistant to kanamycin and colchicine. The urease test, bile esculin hydrolysis, and glucose, lactose, and sucrose fermentation were all negative.

\section{Statistical Analysis}

Samples were described using mean and standard deviation. Median, 25th, and 75th percentiles of measured quantity were also reported. It is because of skewness in empirical distribution of measurements and undetectable of some measured IgA and IgG titers (those measurements were actually positive and less than 1. However, due to uncertainty of their exact values, they were replaced with 1). So it is noteworthy that the estimated mean and standard deviation are very low biased upward. The Mann-Whitney $U$ test was applied for comparison of two groups. The Kruskal-Wallis and median tests were applied to compare more than two groups. In case of significant differences between more than two groups, Dunn's nonparametric comparison for post hoc testing was used. Differences were considered significant when $p<0.05$, and all analyses were performed using SPSS version 20 .

\section{Results}

The IgG and IgA antibody titers at one week after booster injection were undetectable in groups III, IV, V, and VI. Based on MannWhitney, significant differences were noted between groups III-VI and groups I and II (Tables 2 and 3 and Figs 4 and 5, $p<0.001$ ); this indicates that FKWC stimulated the immune system, but a combination of IFA and PG buffer had no significant effect on the immune system. At 2 and 10 weeks after final inoculation of viable bacteria, this significant difference was still present (Table 4 and Fig. 6).

ANOVA found a significant difference in the mean bacterial count in subgingival plaque at 10 weeks after final inoculation between groups III and V and other groups ( $p<0.001$ ) (Table 4 and Fig. 6).

Table 2: IgA titer 1 week after the booster and 2, 10 weeks after the last inoculation

\begin{tabular}{|c|c|c|c|c|c|c|c|c|}
\hline & Group & $n$ & Mean $^{\&}$ & Std. deviation & P25 & Median & P75 & pvalue \\
\hline \multirow{6}{*}{$\begin{array}{l}\lg A \text { at one week } \\
\text { after booster* }\end{array}$} & Group I & 11 & 1212.73 & 2947.077 & 10.00 & 100.00 & 1000.00 & \multirow[t]{6}{*}{$0.748^{+}$} \\
\hline & Group II & 11 & 2930.09 & 4556.101 & 10.00 & 100.00 & 10000.00 & \\
\hline & Group III & 11 & 4.27 & 4.541 & 1.00 & 1.00 & 10.00 & \\
\hline & Group IV & 11 & 1.00 & 0.000 & 1.00 & 1.00 & 1.00 & \\
\hline & Group V & 10 & 4.60 & 4.648 & 1.00 & 1.00 & 10.00 & \\
\hline & Group VI & 8 & 1.00 & .000 & 1.00 & 1.00 & 1.00 & \\
\hline \multirow{6}{*}{$\begin{array}{l}\text { IgA } 2 \text { weeks after } \\
\text { inoculation** }\end{array}$} & Group I & 11 & 1237.27 & 2936.338 & 100.00 & 100.00 & 1000.00 & \multirow[t]{6}{*}{$<0.001^{++}$} \\
\hline & Group II & 11 & 2938.27 & 4550.410 & 10.00 & 100.00 & 10000.00 & \\
\hline & Group III & 11 & 6.73 & 4.541 & 1.00 & 10.00 & 10.00 & \\
\hline & Group IV & 11 & 1.00 & 0.000 & 1.00 & 1.00 & 1.00 & \\
\hline & Group V & 10 & 5.50 & 4.743 & 1.00 & 5.50 & 10.00 & \\
\hline & Group VI & 8 & 1.00 & 0.000 & 1.00 & 1.00 & 1.00 & \\
\hline \multirow{6}{*}{$\begin{array}{l}\text { IgA } 10 \text { weeks after the } \\
\text { last inoculation** }\end{array}$} & Group I & 11 & 50.909 & 47.0010 & 10.000 & 10.000 & 100.000 & \multirow[t]{6}{*}{$0.229^{++}$} \\
\hline & Group II & 11 & 42.727 & 45.4072 & 10.000 & 10.000 & 100.000 & \\
\hline & Group III & 11 & 14.091 & 28.8460 & 1.000 & 10.000 & 10.000 & \\
\hline & Group IV & 11 & 1.000 & 0.0000 & 1.00 & 1.00 & 1.00 & \\
\hline & Group V & 10 & 26.200 & 39.0692 & 7.750 & 10.000 & 32.500 & \\
\hline & Group VI & 8 & 1.000 & 0.0000 & 1.00 & 1.00 & 1.00 & \\
\hline
\end{tabular}

\&Value 1 means that it is undetectable (real value is positive and less than 1)

*Because of no variability in or undetectable median of IgA titer one week after booster, only group I was compared with group II

**Because of no variability in or undetectable median of IgA titer two weeks after inoculation, only groups I-III and V were compared to each other

${ }^{+}$Extracted from Mann-Whitney test

${ }^{++}$Extracted from median test 
Table 3: IgG titer 1 week after the booster and 2, 10 weeks after the last inoculation

\begin{tabular}{|c|c|c|c|c|c|c|c|c|}
\hline & Group & $n$ & Mean $^{\&}$ & Std. deviation & P25 & Median & P75 & $p$ value \\
\hline \multirow{6}{*}{$\begin{array}{l}\text { IgG at one week after } \\
\text { booster* }\end{array}$} & Group I & 11 & 17363.64 & 27540.053 & 10000.00 & 10000.00 & 10000.00 & \multirow[t]{6}{*}{$0.332^{+}$} \\
\hline & Group II & 11 & 49272.73 & 48678.724 & 10000.00 & 10000.00 & 100000.00 & \\
\hline & Group III & 11 & 1.00 & 0.000 & 1.00 & 1.00 & 1.00 & \\
\hline & Group IV & 11 & 1.00 & 0.000 & 1.00 & 1.00 & 1.00 & \\
\hline & Group V & 11 & 1.00 & 0.000 & 1.00 & 1.00 & 1.00 & \\
\hline & Group VI & 11 & 1.00 & 0.000 & 1.00 & 1.00 & 1.00 & \\
\hline \multirow{6}{*}{$\begin{array}{l}\text { IgG } 2 \text { weeks after } \\
\text { inoculation** }\end{array}$} & Group I & 11 & 41909.09 & 46131.236 & 10000.00 & 10000.00 & 100000.00 & \multirow[t]{6}{*}{$<0.001^{++}$} \\
\hline & Group II & 11 & 49272.73 & 48678.724 & 10000.00 & 10000.00 & 100000.00 & \\
\hline & Group III & 11 & 23.09 & 38.261 & 1.00 & 10.00 & 10.00 & \\
\hline & Group IV & 11 & 1.00 & 0.000 & 1.00 & 1.00 & 1.00 & \\
\hline & Group V & 10 & 124.30 & 310.179 & 1.00 & 10.00 & 100.00 & \\
\hline & Group VI & 8 & 1.00 & 0.000 & 1.00 & 1.00 & 1.00 & \\
\hline \multirow{6}{*}{$\begin{array}{l}\text { IGg } 10 \text { weeks after } \\
\text { the last inoculation** }\end{array}$} & Group I & 11 & 255.455 & 369.0898 & 100.000 & 100.000 & 100.000 & \multirow[t]{6}{*}{$0.012^{++}$} \\
\hline & Group II & 11 & 509.091 & 470.0097 & 100.000 & 100.000 & 1000.000 & \\
\hline & Group III & 11 & 14.909 & 28.5638 & 1.000 & 10.000 & 10.000 & \\
\hline & Group IV & 11 & 1.818 & 2.7136 & 1.000 & 1.000 & 1.000 & \\
\hline & Group V & 10 & 24.400 & 40.0699 & 1.000 & 10.000 & 32.500 & \\
\hline & Group VI & 8 & 1.000 & 0.0000 & 1.00 & 1.00 & 1.00 & \\
\hline
\end{tabular}

\&Value 1 means that it is undetectable (real value is positive and less than 1)

* Because of no variability in or undetectable median of IgG titer one week after booster, only group I was compared with group II

**Because of no variability in or undetectable median of IgG titer two weeks after inoculation, only groups I-III and V were compared to each other

${ }^{+}$Extracted from Mann-Whitney test

${ }^{++}$Extracted from median test

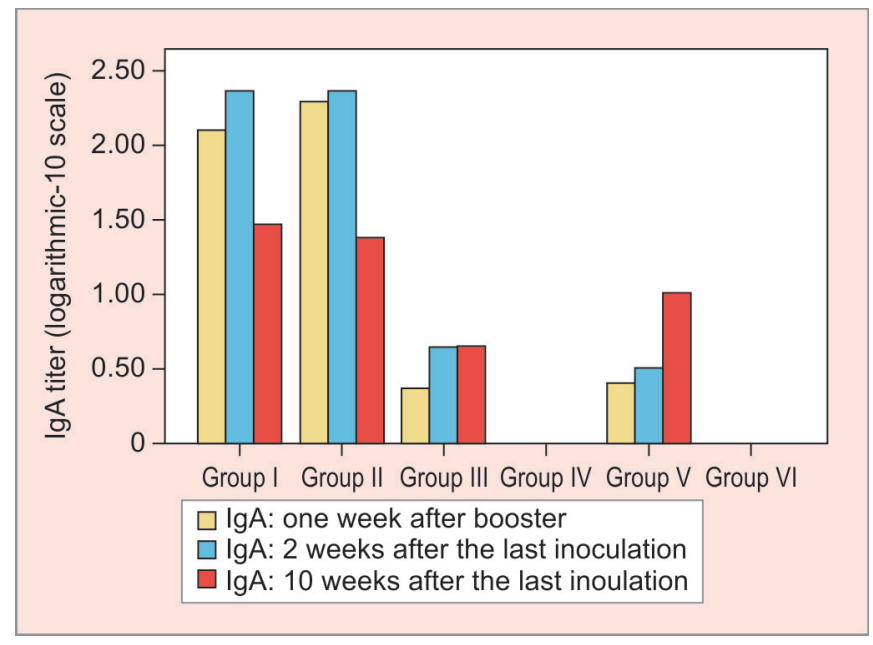

Fig. 4: IgA titer 1 week after the booster and 2, 10 weeks after the last inoculation

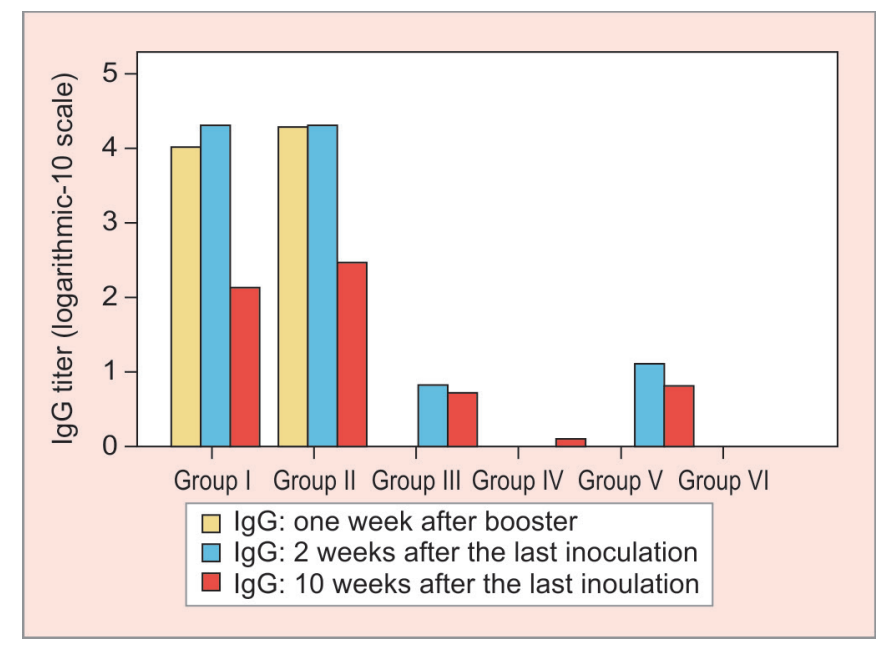

Fig. 5: IgG titer 1 week after the booster and 2, 10 weeks after the last inoculation

Table 4: Bacterial count at 10 weeks after inoculation

\begin{tabular}{llrrrrrr}
\hline Group & $n$ & \multicolumn{1}{c}{ Mean } & Std. deviation & \multicolumn{1}{c}{$P 25$} & Median & \multicolumn{1}{c}{$P 75$} & $p$ value \\
\hline Group I & 11 & 27.273 & 46.7099 & 0.000 & 0.000 & 100.000 & $<0.001^{* *}$ \\
Group II & 11 & 18.182 & 40.4520 & 0.000 & 0.000 & 0.000 & \\
Group III & 11 & 927.273 & 663.4620 & 500.000 & 900.000 & 1200.000 & \\
Group IV & 11 & 18.182 & 40.4520 & 0.000 & 0.000 & 0.000 & \\
Group V & 10 & 630.000 & 434.7413 & 275.000 & 600.000 & 975.000 & \\
Group VI* & 8 & 0.000 & 0.0000 & 0.000 & 0.000 & 0.000 & \\
\hline
\end{tabular}

*Because of no variability in bacterial count, this group was dropped from comparison

**Extracted from Kruskal-Wallis test 


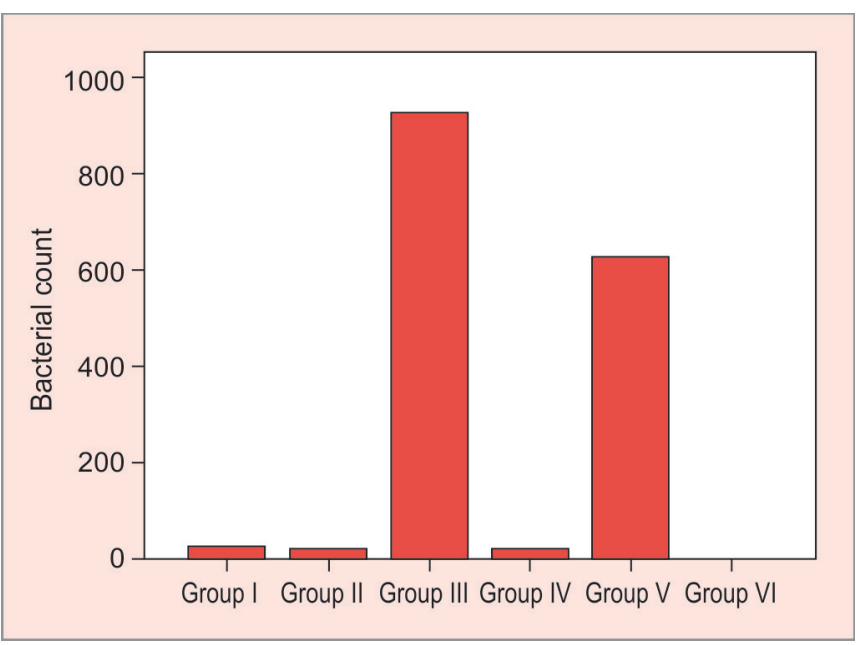

Fig. 6: Bacterial count at 10 weeks after inoculation

This indicated that vaccination with FKWC prevented the colonization of $P$. gingivalis in the subgingival plaque, and according to the MannWhitney test, no significant difference was noted between groups III and $\mathrm{V}(p=138)$.

ANOVA was also used to assess horizontal bone loss 10 weeks after final inoculation of bacteria, which showed a significant difference among the groups. Tukey's HSD test for pairwise comparisons showed a significant difference between groups I, II, IV, and VI and groups III and V (Table 5); this finding supported the use of FKWC vaccine for prevention of periodontal disease and bone loss (Table 5).

\section{Discussion}

Conventional periodontal treatments are based on mechanical and surgical methods and prescription of antibiotics, which are time-consuming and difficult for patients. ${ }^{4}$

Unfortunately, there is no method for humans based on immunization (vaccination) to prevent such diseases.

The tissue damage occurring around tooth and periodontal tissue is caused by direct toxic action of bacteria, as well as the host's inflammatory response to limit the pathogenic factor in order to minimize the tissue damage. ${ }^{1,2,4}$

Mechanical methods cannot heal the bone loss around the tooth perfectly, because they are not capable of eliminating the biological factor that caused the bone loss. ${ }^{1,2}$

For this reason, in this study we considered obtaining acquired immunity against $P$. gingivalis that is one of the main factors responsible for the periodontal disease. $P$. gingivalis has different virulence factors and in several studies, researchers have used whole-cell bacteria, fimbriae protein, arginine-lysine protein, or DNA as immunogenic factors for evaluating animal's acquired immunity response for prevention of periodontal disease. ${ }^{1,2,4,9,12,13}$ In this study, we used formalin-killed whole-cell bacteria (FKWC) (Table 1).

The result of this study showed that vaccination with FKWC could protect the animals against $P$. gingivalis and protect them against periodontal disease by acquired immunity.

In this study, the level of bone loss in the vaccinated group (I and II) with FKWC that was exposed to bacterial oral inoculation was almost similar to those of the negative-control group and groups II and IV and had no statistical difference with these groups.

This result shows the capability of FKWC vaccine in stimulating acquired immune system and increasing salivary and serum antibody levels (which were seen) for counteracting $P$. gingivalis that is in regard to studies of Xiaozhe Han et al. in 2014, 2013 and Rajapakse in 2002 and O'Brien-Simpson et al. ${ }^{3-8}$

In a study by Xiaozhe Han et al., they used $P$. gingivalis DNA as the vaccine and they observed that it could protect animals against induced periodontal disease and prevent bone loss. Also, a highlevel serum IgG and salivary IgA was observed. ${ }^{5}$

In this study, the $P$. gingivalis bacterial level in subgingival plaque was significantly low in immunized animals with FKWC in comparison with the positive-control group and group III, and a significant statistical difference was observed that shows prevention of bacterial colonization in subgingival plaque of vaccinated animals and prevention of periodontal disease.

In addition, in this study, antibody levels were measured in particular sequences of time, before and after bacterial inoculation for each group, and it was significantly higher in groups receiving FKWC vaccine before and after 10 weeks from bacterial oral inoculation. This finding is in regard to study of Rajapakse, that used FKWC and RgpA-Kgp, and study of Xiaozhe Han et al. that used bacterial DNA as the immunogenic factor.

Immune system stimulation and increasing antibody levels against a pathogen are the key for immunization so that in the second encounter, the body will be able to secrete antibodies against that pathogen. ${ }^{1,2,4}$

In this study, $\lg A$ salivary antibody and serum IgG were significantly higher before and after 10 weeks from bacterial inoculation that is in regard to studies of Xiaozhe Han et al., Rajapakse, and O'Brien-Simpson et al. ${ }^{4-8}$

This finding justifies the decrease in subgingival plaque bacterial load and eventually prevention of bone loss and periodontal disease.

The study of Han et al. in 2013 showed that salivary IgA and serum IgG levels and T-lymphocytes proliferation against $P$. gingivalis are increased; also, they found that bone loss is caused by an increase in RANKL in gingival tissue and bone. ${ }^{3}$ In addition, they showed that bone loss was significantly lower in animals receiving anti-RANKL and osteo-protegrin. ${ }^{1-3}$

Table 5: Bone loss at 10 weeks after inoculation

\begin{tabular}{llllllll}
\hline Group & $n$ & Mean & Std. deviation & P25 & Median & P75 & p value \\
\hline Group I & 11 & 283.7791 & 51.11583 & 230.9100 & 300.4500 & 323.0100 & $<0.001^{*}$ \\
Group II & 11 & 288.0891 & 52.50701 & 257.5000 & 292.2100 & 319.6200 & \\
Group III & 11 & 478.3600 & 56.87869 & 440.3700 & 454.5300 & 541.3600 & \\
Group IV & 11 & 267.3545 & 86.21713 & 220.4400 & 282.3900 & 321.1000 & \\
Group V & 10 & 425.0790 & 50.80128 & 391.2525 & 418.8600 & 454.9675 & \\
Group VI & 8 & 237.1650 & 64.81926 & 199.6750 & 229.7500 & 301.7525 & \\
\hline
\end{tabular}

*Extracted from Kruskal-Wallis test 
IgG stimulates phagocytosis and antibody-dependent cellular cytotoxicity in macrophages and NKCs via FcyRII receptor. ${ }^{1,2,14}$ Also, IgG antibody prevents mast cells degranulation while phagocytosis and endocytosis. ${ }^{10,13,15}$ In addition, it is observed that the IgG-2a-specific antibody prevents Rgp-Kgp linkage in gingival tissues and gingival crevicular fluid (GCF). ${ }^{10,13,15}$ This specific antibody in GCF and saliva prevents $P$. gingivalis linkage and colonization.

In a recent study by Bender et al. in 2017 evaluating serum antibody levels against $P$. gingivalis in arthritis-rheumatoid patients compared to the control group, they figured out that the serum antibody level against $P$. gingivalis is higher in arthritis-rheumatoid patients which indicates immune system stimulation by this bacteria. ${ }^{16}$

Therefore, this vaccine can stimulate the immune system and lead to acquired immunity against $P$. gingivalis for a limited period of approximately ten weeks and can protect animals against subgingival bacterial colonization and eventually against bone loss and periodontal disease. In future studies, we suggestion that this immunity against $P$. gingivalis assay in the long periods.

\section{Conclusion}

In this study, we showed that vaccination of rats with FKWC $P$. gingivalis increased the serum IgG and salivary IgA antibody titers and limited the colonization of $P$. gingivalis in the subgingival plaque and restricted alveolar bone loss. These findings indicate that this vaccination may be efficient for prevention of periodontal disease in humans as well.

\section{Clinical Significance}

We used formalin-killed whole-cell $P$. gingivalis for vaccination of rats to assess its efficacy to induce an immune response and prevent bone loss, hoping to take a step forward in developing a vaccine for human periodontitis.

\section{ACKnowledgment}

The authors would like to thank the Hamadan University of Medical Sciences Research Center.

\section{References}

1. Newman MG, Takei HH, et al. Carranza's Clinical Periodontology, 12th ed. Canada: WB Saunders Company, 2015.

2. Lindhe J, Lang NP. Clinical periodontology and implant dentistry, 6th ed, Wiley Blackwell, 2015.

3. Han X, Lin X, et al. Porphyromonas gingivalis infection-associated periodontal bone resorption is dependent on receptor activator of
NF-kappaB ligand. Infect Immun 2013;81(5):1502-1509. DOI: 10.1128/ IAI.00043-13.

4. Rajapakse PS, O'Brien-Simpson NM, et al. Immunization with the RgpA-Kgp proteinase-adhesin complexes of Porphyromonas gingivalis protects against periodontal bone loss in the rat periodontitis model. Infect Immun 2002;70(5):2480-2486. DOI: 10.1128/IAI.70.5.2480-2486.2002.

5. Han X, LaRosa KB, et al. DNA-based adaptive immunity protect host from infection-associated periodontal bone resorption via recognition of Porphyromonas gingivalis virulence component. Vaccine 2014;32(2):297-303. DOI: 10.1016/j.vaccine.2013.09.004.

6. O'Brien-Simpson NM, Paolini RA, et al. RgpA-Kgp peptide-based immunogens provide protection against Porphyromonas gingivalis challenge in a murine lesion model. Infect Immun 2000;68(7):40554063. DOI: 10.1128/IAI.68.7.4055-4063.2000.

7. O'Brien-Simpson NM, Pathirana RD, et al. An immune response directed to proteinase and adhesin functional epitopes protects against Porphyromonas gingivalis-induced periodontal bone loss. J Immunol 2005;175(6):3980-3989. DOI: 10.4049/jimmunol.175.6.3980.

8. O'Brien-Simpson NM, Pathirana RD, et al. Porphyromonas gingivalis RgpA-Kgp proteinase-adhesin complexes penetrate gingival tissue and induce proinflammatory cytokines or apoptosis in a concentration-dependent manner. Infect Immun 2009;77(3):12461261. DOI: 10.1128/IAI.01038-08.

9. Pathirana RD, O'Brien-Simpson NM, et al. Host immune responses to Porphyromonas gingivalis antigens. Periodontol 2000;52(1):218-237. DOI: 10.1111/j.1600-0757.2009.00330.x.

10. Wilensky A, Polak D, et al. The role of RgpA in the pathogenicity of Porphyromonas gingivalis in the murine periodontitis model. J Clin Periodontol 2013;40(10):924-932. DOI: 10.1111/jcpe.12139.

11. Condorelli F, Scalia G, et al. Isolation of Porphyromonas gingivalis and detection of immunoglobulin A specific to fimbrial antigen in gingival crevicular fluid. J Clin Microbiol 1998;36(8):2322-2325.

12. Pathirana RD, O'Brien-Simpson NM, et al. The role of the RgpA-Kgp proteinase-adhesin complexes in the adherence of Porphyromonas gingivalis to fibroblasts. Microbiology 2008;154(Pt 10):2904-2911. DOI: 10.1099/mic.0.2008/019943-0.

13. Sharma A, Honma K, et al. Oral immunization with recombinant Streptococcus gordonii expressing porphyromonas gingivalis FimA domains. Infect Immun 2001;69(5):2928-2934. DOI: 10.1128/ IAI.69.5.2928-2934.2001.

14. Marchesan JT, Morelli T, et al. Divergence of the systemic immune response following oral infection with distinct strains of Porphyromonas gingivalis. Mol Oral Microbiol 2012;27(6):483-495. DOI: 10.1111/omi.12001.

15. Tam V, O'Brien-Simpson NM, et al. Characterization of T cell responses to the RgpA-Kgp proteinase-adhesin complexes of Porphyromonas gingivalis in BALB/c mice. J Immunol 2008;181(6):4150-4158. DOI: 10.4049/jimmunol.181.6.4150.

16. Bender $P$, Burgin $W B$, et al. Serum antibody levels against Porphyromonas gingivalis in patients with and without rheumatoid arthritis - a systematic review and meta-analysis. Clin Oral Investig 2017;21(1):33-42. DOI: 10.1007/s00784-016-1938-5. 